\title{
Ante el desafío comunitario de proteger la biodiversidad
}

\author{
Stavros Dimas ${ }^{1}$
}

Casi ya ha transcurrido una década desde que los Jefes de Estado y Primeros ministros europeos se fijaron el objetivo de frenar el deterioro de la biodiversidad en la Unión Europea para el año 2010. Desde entonces, se han realizado ciertos progresos. Se han diseñado nuevas políticas y se han puesto en práctica medidas legislativas. Se han reforzado políticas ya existentes. Nuestro conocimiento de las realidades subyacentes que regulan la biodiversidad, también ha mejorado. Pero a pesar de estos progresos realizados, hay un creciente reconocimiento de que no se podrán cumplir los objetivos fijados para el año 2010.

Las razones de la pérdida de biodiversidad son bien conocidas: destrucción de hábitats, contaminación, sobreexplotación, especies invasoras y más recientemente, el cambio climático. La combinación de todos estos factores es terrible. El índice global de extinción de especies es al menos 1000 veces mayor que el ritmo natural de desaparición de especies. Se estima que una de cada ocho especies de aves, un cuarto de todos los mamíferos y un tercio de todos los anfibios, se encuentran en peligro. Los científicos hablan ahora de la sexta gran causa planetaria de extinción. La última tuvo lugar hace 65 millones de años y en ella se vio la desaparición de los dinosaurios.

La amenaza derivada de la pérdida de biodiversidad es tan grave como la amenaza del cambio climático. La biodiversidad es un concepto relativamente nuevo -se acuñó por primera vez hace 25 años- Pero lo que engloba es tan simple como amplio, pues abarca todo. La biodiversidad es la vida en la tierra. Es sorprendente lo poco que se sabe acerca de la complejidad de la vida. Se ha venido diciendo que los científicos saben con más exactitud cuántas estrellas hay en una galaxia, que el número de especies que viven en nuestro planeta. Pero algo de lo que podemos estar seguros es de la creciente velocidad de desaparición de especies y ecosistemas, fenómeno que se produce a un ritmo jamás conocido antes en nuestra historia.

1 Comisario de medio ambiente. Comisión Europea. 
La razón más obvia para la protección de la naturaleza radica en su valor intrínseco. La naturaleza forma parte de nuestra cultura, de nuestra historia e incluso de nuestras religiones. Tenemos la obligación moral de ser cuidadosos vigilantes del planeta. Nuestra tecnología es capaz de mandar un hombre a la Luna, pero no hay tecnología que nos permita sustituir una especie, por simple que sea, una vez que ha desaparecido. Cuando destruimos la naturaleza, estamos privando a futuras generaciones de opciones para su supervivencia y desarrollo. No es sólo un comportamiento irresponsable, es también inmoral.

Al igual que ocurre con el cambio climático, el proteger la biodiversidad, actúa también en nuestro propio beneficio. La destrucción de la biodiversidad, acarrea también costes económicos reales. La Naturaleza suministra el sistema de soporte vital del que depende la vida de todo el planeta. La naturaleza nos proporciona alimentos, nos da materias primas y medicinas. Purifica el aire y el agua. En un estudio patrocinado por la Comisión Europea, Alemania y Reino Unido, se ha estimado que la destrucción de la naturaleza y de los vitales servicios que los ecosistemas proporcionan, podrían hacia el año 2050 costar a la humanidad el seis por ciento del PIB cada año.

El problema es que aunque son reales y pueden calcularse, estos costes no son comprendidos a escala global. Los beneficios a medio plazo de disponer de un agua más limpia, un aire más limpio y bonitos paisajes, pierden terreno ante las ganancias a corto plazo derivadas de la tala a matarrasa de un bosque o de un desarrollo sin freno. En un mundo donde la palabra desarrollo se asocia frecuentemente con crecimiento económico, corremos el riesgo de perseguir un desarrollo a toda costa. El huracán Katrina apareció como un acontecimiento positivo en el PIB norteamericano. Lo mismo pasó con el drenaje de los humedales de Nueva Orleans, lo que hizo que el impacto negativo del huracán fuera mucho mayor.

Si éste es el progreso que pretendemos, entonces, la naturaleza no tiene ninguna posibilidad. Lo que necesitamos hacer es comprender mejor el valor auténtico de la naturaleza para tenerlo en cuenta en nuestras decisiones políticas. Mientras sigamos pensando que la utilización de los recursos naturales es algo gratuito, continuaremos explotándolos. Debemos contemplar el mundo de forma distinta si queremos enfocar de otro modo la forma tradicional de hacer negocios. Los bancos de peces se están extinguiendo. Las tierras dejan de ser fértiles. El mundo silvestre está desapareciendo. Esto es todo lo contrario a un desarrollo sostenible.

Necesitamos apartarnos de la idea de que podemos explotar los recursos naturales indefinidamente y pensar que debemos gestionarlos cuidadosamente. Esto ha motivado ciertas iniciativas que van más allá del PIB y tratan de obtener nuevos modos de medir el progreso. Debemos intentar comprender mejor el valor de la naturaleza colocándola por encima del bienestar humano. Lo cierto es que nuestro bienes454 importancia. 
Para citar solo un ejemplo: La deforestación totaliza cerca de un 20\% del total de emisiones del llamado efecto invernadero. Más de la mitad de todas las emisiones de la Unión Europea. Si abordamos el calentamiento global con éxito, necesitaremos proteger los bosques y reconocer su valor como reguladores del clima. Esto tendrá también la ventaja de proteger algunas de las zonas más ricas del planeta en términos de diversidad natural. Los bosques son las catedrales de la naturaleza. En Panamá, un estudio de solo 19 árboles llegó a descubrir 1.200 tipos de escarabajos, de los que 1000 eran anteriormente desconocidos para la ciencia.

El proteger la naturaleza es un asunto básico en la cooperación internacional. La naturaleza no entiende de fronteras políticas trazadas en los mapas y las encuestas de opinión nos indican un creciente respaldo popular hacia medidas enérgicas tomadas a escala europea. Hace más de 30 años, la directiva europea sobre aves silvestres fue una de las primeras medidas legislativas adoptadas por la EU referidas al medio ambiente. Y se han logrado notables éxitos a lo largo de los últimos 30 años. La red Natura 2000 está a punto de ser completada. Con 25.000 espacios, cubre una zona más amplia que el territorio de cualquiera de los estados miembros. Constituye la zona más extensa de protección medioambiental del planeta y es, sin lugar a dudas, uno de los logros más importantes dentro de la política medioambiental de la Unión Europea. La protección legal brindada por la directiva de hábitats ha frenado la destrucción de zonas naturales insustituibles y ha regulado la actividad cinegética sostenible. Apoyada por la financiación de la EU, ha jugado un papel fundamental en la protección de algunas de las especies amenazadas de extinción.

También se han logrado progresos en la protección de ecosistemas marinos y fluviales gracias a la puesta en marcha de la directiva marco de aguas y la adopción de nuevas estrategias sobre las aguas del mar. Las actividades agrícolas sostenibles se van extendiendo cada vez más. La Comisión está desarrollando opciones con vistas a una estrategia comunitaria encaminada a abordar la creciente amenaza de las especies invasoras. En el último año, hemos lanzado nuevas iniciativas encaminadas a frenar la tala ilegal de árboles, a combatir la deforestación ilegal y a promover formas de consumo sostenibles desde el punto de vista medio-ambiental.

Hemos hecho progresos en muchos campos, pero la ciencia nos dice que la diversidad europea no se encuentra todavía en una situación saludable. Alrededor del 80\% de los espacios europeos más valiosos permanecen en una situación de "amenaza" o son "vulnerables" y la situación es parecida para las especies animales. Si queremos tener la oportunidad de parar la pérdida de biodiversidad, tendremos que redoblar nuestros esfuerzos. Esto fue lo que impulsó a la Comisión a patrocinar la conferencia sobre biodiversidad que tuvo lugar en Atenas. A finales de abril, los científicos, las ONG y gobernantes de todo el mundo se reunieron para tratar de identificar los problemas y trazar las actuaciones a seguir para preservar la biodiversidad tras el año 2010.

El gran interés en la conferencia reflejó la importancia de la materia. Las conclusiones principales -El Mensaje desde Atenas- resaltaron los aspectos sobre los que nos deberemos concentrar en el futuro. 
Para lograr auténticos progresos necesitamos un nuevo enfoque de por qué es importante la biodiversidad. Tenemos que dejar de verla como un asunto meramente medioambiental. Necesita penetrar en la política general concediéndole una importancia parecida a la que ha tenido el problema del cambio climático durante los tres años pasados. Si esto va a ocurrir, necesitamos desarrollar y comunicar un mejor entendimiento de por qué los ecosistemas sanos tendrán -y tienen- un impacto sobre nuestra calidad de vida presente y futura. Como primera medida, necesitaremos comprender mejor la racionalidad económica de la protección de la biodiversidad y asegurarnos de que son tenidos en cuenta los valores reales de los servicios medioambientales a la hora de diseñar políticas públicas.

De forma más inmediata, necesitamos ponernos de acuerdo sobre los futuros objetivos políticos dado que la fecha tope del 2010 casi ya ha finalizado. El nuevo objetivo post 2010 debería ser ambicioso, medible, de fácil comprensión y necesita reconocer el valor de los ecosistemas sanos y los servicios que nos prestan. Necesitamos ponernos manos a la obra inmediatamente, ya que probablemente se fijen nuevos objetivos durante la primera mitad del próximo año.

El mensaje de Atenas identificaba también un conjunto de diversos objetivos donde se necesita actuar con urgencia. Los europeos son cada vez más conscientes del valor de la biodiversidad dentro de la Unión Europea, pero todavía no entienden bien la negativa huella que actividad del continente produce en la biodiversidad del resto del Planeta. Otro elemento clave será la integración de la biodiversidad en otras políticas -tales como la agricultura, la pesca, el desarrollo regional, el transporte, la energía el comercio y el desarrollo- que pueden tener un impacto significativo sobre la biodiversidad tanto dentro de la Unión Europea como a escala global. Necesitamos promover medidas legislativas de forma más coordinada. Sería necesario también desarrollar realizar un enfoque coherente en cuanto a la planificación territorial siempre que sea posible.

Las Naciones Unidas han declarado el año 2010 año internacional de la biodiversidad. Será sin duda un foco de atención principal en el seno de la Unión Europea. Deseo fervientemente que el Mensaje desde Atenas sirva de inspiración para la próxima generación de políticas que, cuando se implemente adecuadamente, frenen de manera efectiva la pérdida de la biodiversidad en Europa. 